\title{
Antipsychotic-associated weight gain: management strategies and impact on treatment adherence
}

\author{
This article was published in the following Dove Press journal: \\ Neuropsychiatric Disease and Treatment \\ 22 August 2017 \\ Number of times this article has been viewed
}

\section{Madhubhashinee \\ Dayabandara \\ Raveen Hanwella \\ Suhashini Ratnatunga \\ Sudarshi Seneviratne \\ Chathurie Suraweera \\ Varuni A de Silva}

Department of Psychiatry, Faculty of Medicine, University of Colombo, Colombo, Sri Lanka
Correspondence: Madhubhashinee

Dayabandara

Department of Psychiatry, Faculty

of Medicine, University of Colombo,

25, Kynsey Road, Colombo 08,

Sri Lanka 00800

Tel +94 77779232 I

Email madhudayabandara@yahoo.com

\begin{abstract}
Antipsychotic-induced weight gain is a major management problem for clinicians. It has been shown that weight gain and obesity lead to increased cardiovascular and cerebrovascular morbidity and mortality, reduced quality of life and poor drug compliance. This narrative review discusses the propensity of various antipsychotics to cause weight gain, the pharmacologic and nonpharmacologic interventions available to counteract this effect and its impact on adherence. Most antipsychotics cause weight gain. The risk appears to be highest with olanzapine and clozapine. Weight increases rapidly in the initial period after starting antipsychotics. Patients continue to gain weight in the long term. Children appear to be particularly vulnerable to antipsychotic-induced weight gain. Tailoring antipsychotics according to the needs of the individual and close monitoring of weight and other metabolic parameters are the best preventive strategies at the outset. Switching to an agent with lesser tendency to cause weight gain is an option, but carries the risk of relapse of the illness. Nonpharmacologic interventions of dietary counseling, exercise programs and cognitive and behavioral strategies appear to be equally effective in individual and group therapy formats. Both nonpharmacologic prevention and intervention strategies have shown modest effects on weight. Multiple compounds have been investigated as add-on medications to cause weight loss. Metformin has the best evidence in this respect. Burden of side effects needs to be considered when prescribing weight loss medications. There is no strong evidence to recommend routine prescription of add-on medication for weight reduction. Heterogeneity of study methodologies and other confounders such as lifestyle, genetic and illness factors make interpretation of data difficult.
\end{abstract}

Keywords: antipsychotics, weight gain, weight-reducing agents, metabolic, treatment adherence

\section{Introduction}

Many factors contribute to weight gain in patients with schizophrenia or psychosis. Sedentary lifestyle, unhealthy food habits, genetic susceptibility and antipsychotic treatment are considered the main contributors. Antipsychotic-induced weight gain (AIWG) is an important concern in the management of patients treated for psychosis.

In addition to weight gain, antipsychotics are also known to impair glucose metabolism, increase cholesterol and triglyceride levels and cause arterial hypertension, leading to metabolic syndrome. ${ }^{1}$ Metabolic syndrome will increase the risk of diabetes mellitus by five times and cardiovascular illness by two times over the next 5-10 years. ${ }^{2}$

Prevalence of metabolic syndrome is high in schizophrenia. A meta-analysis of 77 publications reported an overall rate of $32.5 \%(95 \% \mathrm{CI}=30.1 \%-35 \%){ }^{3}$ Waist size was the most useful predictor of metabolic syndrome. ${ }^{3}$ This study estimated that an alarming proportion of $49.4 \%$ was obese according to Adult Treatment Panel III of the National Cholesterol Education Program criteria. A similar meta-analysis conducted in patients presenting in the first episode of schizophrenia found lower prevalence rates 
of metabolic syndrome $(\sim 10 \%)$ in both unmedicated and medicated patients. ${ }^{4}$ However, rates of obesity were still high in both these groups at $26.6 \%$ and $22 \%$, respectively. ${ }^{4}$

This increased prevalence of metabolic syndrome and obesity contributes to the lower life expectancy and increased mortality rates in schizophrenia. ${ }^{5}$ Olfson et al reported that adult patients with schizophrenia were 3.5 times (all-cause standardized mortality ratio $3.7,95 \% \mathrm{CI}: 3.7-3.7)$ more likely to die in the follow-up period than adults in the general population. ${ }^{5}$ Cardiovascular disorders had the highest standardized mortality ratio of 3.5 (95\% CI: 3.5-3.6). Another meta-analysis of 13 cohort studies reported a pooled relative risk of 1.53 (95\% CI: 1.27-1.86) for the incidence of cardiovascular disorders and a relative risk of 1.71 (95\% CI: 1.19-2.46) for stroke in patients with schizophrenia, when compared with the reference group. ${ }^{6}$

Prevention of AIWG at the outset would be the best strategy, as opposed to treatment of weight gain and related problems. The possibility of subsequent weight gain and its implications are often not adequately considered by clinicians when commencing antipsychotics. There are shortcomings in the monitoring of weight and other metabolic risk factors in patients on antipsychotics. ${ }^{7,8}$ This leaves a population of patients with iatrogenically caused weight gain, who require interventions to reduce morbidity.

\section{Likelihood of antipsychotics to cause weight gain}

Interest in antipsychotics causing weight gain was awakened after the landmark study by Allison et al. This was the first meta-analysis on the subject. The study evaluated weight gain due to both first- and second-generation antipsychotics (FGAs and SGAs, respectively) at standard doses for 10 weeks. ${ }^{9}$ Patients on placebo appeared to have lost weight, while most of the antipsychotics caused weight gain. A mean weight loss of $0.39 \mathrm{~kg}$ was reported for molindone, while clozapine, olanzapine, thioridazine, sertindole, chlorpromazine and risperidone were all reported to cause significant weight gain varying from 4.45 to $2.10 \mathrm{~kg}$. ${ }^{9}$

Subsequent meta-analyses have confirmed these findings. The multiple-treatments meta-analysis by Leucht et al using 6-week data reported that all antipsychotics except haloperidol, lurasidone and ziprasidone caused weight gain. ${ }^{10}$ Olanzapine and zotepine caused significantly more weight gain than most other antipsychotics.

Another head-to-head meta-analysis reported that olanzapine and clozapine cause the highest amount of weight gain, while quetiapine, risperidone and sertindole caused intermediate amounts. Intermediate to low level of weight gain was observed with aripiprazole and amisulpiride. Ziprasidone caused the least amount of weight gain. ${ }^{11}$

A meta-analysis by De Hert et al observed that the newer antipsychotics asenapine, iloperidone, paliperidone and lurasidone caused significant weight gain. Clinically significant weight gain of more than $7 \%$ was caused by all the drugs except lurasidone. ${ }^{12}$

A recent meta-analysis by Bak et al included randomized controlled trials (RCTs) and controlled trials published after 1999, irrespective of diagnosis. ${ }^{13}$ Except for aripiprazole, amisulpride and ziprasidone, most antipsychotics including FGAs showed significant weight gain. Similar results were found in antipsychotic-naïve groups, where significant weight gain was observed even during the first 6 weeks. Proportion of patients with clinically significant gain of more than $7 \%$ of baseline weight increased over time for all antipsychotics. Interestingly, a significant proportion of patients also showed a clinically significant loss of more than $7 \%$ of baseline weight with amisulpride, aripiprazole, asenapine, olanzapine, paliperidone and ziprasidone.

In patients presenting in the first episode psychosis, Tek et al reported $3.22 \mathrm{~kg}$ of weight gain in the short term and $5.3 \mathrm{~kg}$ gain in the long term, compared to placebo. ${ }^{14}$ This study replicated the findings of Leucht et al. ${ }^{10}$

Table 1 ranks the antipsychotics according to the likelihood of causing weight gain, considering the current evidence.

Table I Likelihood of weight gain with antipsychotics

\begin{tabular}{|c|c|}
\hline Antipsychotic & $\begin{array}{l}\text { Propensity to } \\
\text { cause weight gain }\end{array}$ \\
\hline Clozapine & High \\
\hline Olanzapine & $\mathrm{High}^{\mathrm{a}, \mathrm{b}}$ \\
\hline Chlorpromazine & Moderate \\
\hline Quetiapine & Moderate $e^{b}$ \\
\hline Risperidone & Moderate $^{b}$ \\
\hline Paliperidone & Moderate \\
\hline Aripiprazole & Low $^{c}$ \\
\hline Amisulpride & Low $^{c}$ \\
\hline Asenapine & Low \\
\hline Haloperidol & Low $^{d}$ \\
\hline Ziprasidone & Low $^{c, d}$ \\
\hline Lurasidone & Low $^{d}$ \\
\hline
\end{tabular}

Notes: aSignificantly greater increase in weight at $>38$ weeks, when compared with $<6$ weeks period in both antipsychotic previously prescribed and naïve groups in the meta-analysis by Bak et al. ${ }^{13}$ bSignificant weight gain seen in antipsychotic naive group even $<6$ weeks in the meta-analysis by Bak et al. ${ }^{13}$ 'Weight neutral with duration of antipsychotic use in the meta-analysis by Bak et al. ${ }^{13} \mathrm{~d}$ No significant difference in weight when compared with placebo in multiple treatment metaanalysis by Leucht et al. ${ }^{10}$ Data from studies. ${ }^{9-11,13}$ 


\section{Mechanisms underlying weight gain and other metabolic abnormalities caused by antipsychotics}

Multiple mechanisms have been proposed to explain the weight gain propensity of antipsychotics. Amount of weight gain varies with the type of antipsychotic and the individual patient characteristics. Most research has focused on clozapine and olanzapine, the two medications identified to cause the highest weight gain. The high likelihood of weight gain with these medications has been linked to their actions at serotonin 5-HT2A and 5-HT2C, dopamine D2 and D3, histamine $\mathrm{H} 1$ and muscarinic $\mathrm{M} 3$ receptors. ${ }^{15}$ The differential effects on weight have been explained by the differing affinity of medications at these receptors. ${ }^{16,17}$

Antipsychotics affect neuropeptides associated with appetite control and energy metabolism. Leptin and adiponectin are the adipokines produced in white adipose tissue, which have been implicated in AIWG. Increased leptin levels and reduced adiponectin levels have been demonstrated with short-term and long-term olanzapine treatment. ${ }^{18,19}$ Ghrelin, which acts on the arcuate nucleus of the hypothalamus to enhance food intake and adipose tissue deposition, is also affected by antipsychotics. ${ }^{20}$ The changes in leptin, adiponectin and ghrelin levels have been postulated to be due to direct effects of the medications rather than being secondary to weight gain. ${ }^{20}$ On the other hand, effects of antipsychotics on lipid and glucose metabolism have been linked to their effect on weight gain and adiposity, leading to insulin resistance and consequent increased release of triglycerides and very low density lipoproteins from adipocytes. ${ }^{21}$ There is also evidence that antipsychotics increase expression of sterol regulatory element-binding protein $(S R E B P)$ and very low density lipoprotein $(V L D L)$ genes. ${ }^{21,22}$

Genetic polymorphisms may explain the individual variation in AIWG. A recent meta-analysis by Zhang et al identified 13 single-nucleotide polymorphisms from nine genes significantly associated with AIWG. ${ }^{23}$ Single-nucleotide polymorphisms related to $A D R A 2 A, D R D 2,5-H T R 2 C$ and $M C 4 R$ genes showed the largest effect size, indicating that candidate genes for weight gain are also linked to receptors by which antipsychotics exert their therapeutic effects.

\section{Timeline for weight gain}

There is rapid weight gain in the first few weeks after commencing antipsychotics. ${ }^{11}$ The rate of weight gain then gradually decreases and flattens over several months. Time taken to plateau was different for each antipsychotic, ranging from 4 to 9 months for olanzapine and from 42 to 46 months for clozapine. ${ }^{11}$ This indicates that patients would continue to gain weight for $1-4$ years. It is consistently reported that patients continue to gain weight over time. ${ }^{11,24}$

An interesting finding described by Bak et al was that weight increased more significantly during the period beyond 38 weeks than within the first 6 weeks for olanzapine and FGA group and for olanzapine alone in antipsychoticnaïve group. ${ }^{13}$

Factors associated with rapid weight gain in the initial period were younger age, lower baseline body mass index (BMI), more robust response to antipsychotic and increase in appetite. Rapid weight gain of more than $5 \%$ in the first month is the best predictor for significant long-term weight gain. ${ }^{25}$

\section{AIWG in children and adolescents}

In many countries, antipsychotic prescription in children has markedly increased over the past two decades. The prescriptions are mainly for SGAs. ${ }^{26}$ The Food and Drug Administration has approved some SGAs for use in children. The prescribing trends show an increase in approved and off-label prescriptions. ${ }^{27}$ Multiple RCTs have shown that SGAs are effective in childhood mental disorders, but the benefits are limited by the risks of both metabolic and neurologic side effects. ${ }^{28}$

Weight gain is one of the most troublesome side effects in children, with up to $80 \%$ of children showing significant weight gain. More weight gain had been observed in adolescent patients than in older patients. ${ }^{29}$ Correll et al argued that weight gain was more in the young due to less prior antipsychotic exposure compared to adults. ${ }^{24}$ Weight gain in the young is more than in adult patients with first episode or chronic schizophrenia. The highest weight gain is with olanzapine, followed by clozapine, risperidone and aripiprazole, similar to adult patients. ${ }^{30}$ Differences in weight gain have been noted according to the diagnosis. Patients with autism treated with antipsychotics had greater weight gain. ${ }^{30}$ A higher propensity to gain weight is also seen in patients with schizophrenia. ${ }^{30}$

In contrast to adults, children are physically and emotionally more vulnerable to the adverse effects of medications. Children are physiologically different from adults due to ongoing growth and development. Peer perception too plays a significant role. ${ }^{31}$ Changes in the physical appearance can lead to body image issues and problems with self-esteem, which in turn could lead to poor compliance with medication. ${ }^{32}$ Similar to adults, it is important to monitor patients for weight gain once the medication is commenced. 


\section{Impact of weight gain on compliance}

Just as extrapyramidal side effects result in poor compliance with FGAs, weight gain is a cause for treatment noncompliance with SGAs. However, direct evidence linking weight gain to poor adherence is sparse.

A study by Weiden et al found that patients who are obese are 13 times more likely to discontinue medication because of weight gain than nonobese patients. ${ }^{33}$ This was reported in the CATIE study as well, where more patients discontinued olanzapine due to weight gain compared to other medications, despite olanzapine showing the lowest overall discontinuation rate. ${ }^{34,35}$

On the other hand, it has also been observed that weight gain is an indicator of better response to antipsychotics and compliance can be expected to improve as a result. ${ }^{36} \mathrm{~A}$ recent study investigating factors associated with poor adherence in patients with bipolar disorder reported no difference in adherence between weight groups. ${ }^{37}$

The expert consensus guideline by Velligan et al on medication adherence of patients with serious psychiatric illness identified weight gain as a likely factor leading to nonadherence. ${ }^{38}$ The experts recommended customizing interventions to address poor adherence.

Weight gain affects quality of life and self-view of patients. Waist circumference and BMI predict low healthrelated quality of life in patients on antipsychotics. ${ }^{39}$ In the study by Weiden et al, subjective distress over weight gain was found to be the primary mediator of noncompliance. ${ }^{33}$ Weight gain, cognitive side effects and sexual dysfunction were significantly associated with poor satisfaction and distress, especially in females. ${ }^{40} \mathrm{~A}$ longitudinal qualitative study interviewing 63 first episode patients aged 14-35 years showed that a change in self-identity ensued with the change in physical appearance resulting from weight gain. ${ }^{41}$

There is evidence that weight gain in patients is of concern to caregivers. A mailed survey to relatives of patients with schizophrenia found that the relatives rated weight as the second most problematic side effect. ${ }^{42}$ The most troublesome was sedation.

Perkins theorized that adherence to medication is determined by the patients' assessment of benefits of treatment and risks of relapse vs the costs of treatment. Therefore, patients who perceive costs more than benefits require interventions to improve adherence. ${ }^{43}$ These interventions should also include appropriate strategies to manage AIWG.

Despite the evidence that weight gain increases morbidity and mortality and reduces adherence, only one third to half are adequately monitored for the metabolic side effects of antipsychotics. ${ }^{44}$

Interventions that result in weight loss can improve quality of life. A meta-analysis of 36 studies of behavioral or dietary interventions for obesity reported improvement in body image and health-related quality of life following weight loss. ${ }^{45}$ However, another meta-analysis found no significant improvement in mental health or overall healthrelated quality of life after weight loss, though modest improvement in physical health was reported. ${ }^{46}$ Evans et al reported significant improvements in quality of life in a patient cohort on olanzapine introduced to weight reduction strategies (intervention group), as opposed to the control group (no weight reduction strategies introduced) ${ }^{47}$

There is little evidence that specific interventions to treat AIWG improve medication adherence or quality of life. Studies from other patient populations support the claim that introduction of weight management strategies will also improve medication adherence. A study of patients with type 2 diabetes mellitus found that patients who experienced weight loss had significantly better antidiabetic medication adherence compared to patients with weight gain. ${ }^{48}$

A wide range of strategies have been employed to manage AIWG. The objective of this paper was to review the current evidence regarding the effectiveness of different pharmacologic and nonpharmacologic interventions for AIWG.

\section{Methods}

We searched Pubmed, Google Scholar, Database of Abstracts of Reviews of Effects and Cochrane database. We used the following key words: weight, weight gain, weight change, body weight AND antipsychotics, SGAs, FGAs, atypical antipsychotics AND schizophrenia, schizoaffective disorder, psychosis AND non-pharmacological, intervention, diet, exercise, cognitive behavior therapy, pharmacological. We also searched for studies of individual medication by name. We retrieved relevant reviews and RCTs. The number of articles retrieved was not recorded and the quality of articles was not assessed in a systematic way as this is not a systematic review.

\section{Results \\ Management of AIWG}

Interventions that minimize AIWG can be broadly classified as pharmacologic and nonpharmacologic. Pharmacologic interventions consist of switching to another antipsychotic which has less potential to cause weight gain or adding an adjuvant. Nonpharmacologic interventions consist of lifestyle modification and cognitive-behavioral strategies. 


\section{Antipsychotic switching}

Antipsychotic switching is one strategy that can be employed to reduce weight. Medication switching should be carried out after careful consideration of the risk of relapse and this should be done in consultation with the patient. The possibility of causing more weight gain must also be considered when switching medication. Haloperidol, lurasidone, ziprasidone, aripiprazole and amisulpiride are considered the best options according to evidence from meta-analyses..$^{10,11}$

There is limited data from RCT regarding effectiveness of switching antipsychotics to ameliorate AIWG. A Cochrane Review of four RCTs reported a mean weight loss of $1.94 \mathrm{~kg}$ when patients were switched from olanzapine to aripiprazole or quetiapine. ${ }^{49}$ Another meta-analysis reported that switching to aripiprazole resulted in a mean weight reduction of $-2.55 \pm 1.5 \mathrm{~kg} .{ }^{50}$ More significant changes were noted when the switch was from olanzapine to aripiprazole. An RCT reported that switching from olanzapine, quetiapine or risperidone to aripiprazole resulted in improvement in metabolic parameters, but increased the rate of discontinuation. ${ }^{51}$

An industry-sponsored open-label extension study of lurasidone reported a small reduction in mean weight of $-0.1 \mathrm{~kg} .{ }^{52}$ Another open-label study reported that switching to amisulpride resulted in weight reduction when compared to the control group ( $7.8 \pm 6.67$ vs $2.3 \pm 6.23)$. One year extension of three switch studies comparing patients who switched from olanzapine, risperidone or FGA to ziprasidone noted significant reduction of weight for switchers from olanzapine and risperidone, but not from FGAs. ${ }^{33}$

\section{Nonpharmacologic strategies for AIWG}

Most studies have focused on weight reduction strategies as opposed to preventive strategies. Preventive and early intervention strategies are more important than weight reduction strategies in patient management.

Nonpharmacologic strategies include cognitive and behavioral interventions, nutritional counseling and exercise. There is significant heterogeneity in studies evaluating these strategies in terms of study duration, duration of follow-up and intensity of the intervention. Cognitive strategies include understanding eating behaviors and physical well-being. Behavioral interventions include training in problem solving, goal setting, social support and monitoring exercise and eating habits. Dietary advice and nutritional counseling include reducing 500-1,000 kcal/daily from the existing diet and reducing dietary fat to $30 \%$ of energy intake. Exercise interventions consist of 150 minutes of moderate (55\%-69\% of the maximum heart rate) exercise weekly. ${ }^{39}$
These interventions are often referred to as "behavioral lifestyle programs". ${ }^{53}$ Both individual interventions and group interventions have been studied.

A meta-analysis of 10 RCTs which employed the nonpharmacologic interventions consisting of cognitive-behavioral interventions, nutritional counseling and combined nutritional and exercise interventions reported weighted mean difference of $-2.56 \mathrm{~kg}$ (CI: 1.92-3.92) compared to treatment as usual. Subgroup analysis showed no significant differences between trials designed to prevent weight gain and trials designed to treat weight gain. This is in contrast to data from pharmacologic approaches. There were no significant differences between individual and group interventions..$^{54}$

A meta-analysis of $25 \mathrm{RCTs}$ investigating lifestyle interventions aimed at weight loss or weight gain prevention concluded that lifestyle interventions were effective in both weight loss (effect size $=-0.52, P<0.0001$ ) and weight gain prevention (effect size $=-0.84, P=0.0002$ ). The interventions consisted of supervised or nonstructured exercise, dietary counseling, motivational interviewing and cognitive-behavioral therapy. Comparison of individual trials did not show superiority over any specific intervention. Lifestyle interventions had significant beneficial effects on weight loss, waist circumference, triglycerides, fasting glucose and insulin. There was no significant effect on blood pressure or cholesterol. ${ }^{55}$

An RCT comparing an early behavioral intervention with routine care in preventing AIWG in drug-naive first-episode psychosis patients found that the behavioral intervention group gained significantly less weight (mean $=4.1 \mathrm{~kg}$, $\mathrm{SD}=4.0$ ) than the routine care (mean $=6.9, \mathrm{SD}=4.5$ ) during the 3-month follow-up period. Fewer patients in the intervention group $(n=11 ; 39.3 \%)$ showed clinically significant weight gain of $7 \%$, compared to the usual treatment group $(\mathrm{n}=26 ; 78.8 \% ; P<0.002) .{ }^{56}$

\section{Pharmacologic interventions for AIWG}

Several RCTs, meta-analyses and systemic reviews have assessed the effectiveness of pharmacologic interventions in managing AIWG. However, the evidence for routine use of pharmacologic adjuvants is not strong. A meta-analysis of RCTs of behavioral and pharmacologic interventions reported that short-term modest weight loss is possible with nonpharmacologic and selective pharmacologic interventions. ${ }^{39}$

A meta-analysis of 40 trials reported that metformin was the most extensively studied drug. ${ }^{57}$ It was observed that adjunctive medications were initiated simultaneously with antipsychotics in 13 studies (26\%). The adjunctive treatment 
for weight gain was mostly initiated when nonpharmacologic interventions alone were not sufficient or impractical and switching antipsychotics was not practicable. ${ }^{57}$

Metformin has the most evidence of efficacy, while topiramate, sibutramine, aripiprazole and reboxetine are also effective. ${ }^{30,57}$ These drugs prevent or treat weight gain through different mechanisms. For example, metformin and rosiglitazone improve insulin resistance, while aripiprazole, metformin and sibutramine decrease lipid levels. Other drugs investigated are ephedrine, orlistat, nizatidine, cimetidine, naltrexone, amantadine, reboxetine, fluoxetine, dextroamphetamine, d-fenfluramine, famotidine, fluvoxamine, phenylpropanolamine and rosiglitazone.

\section{Metformin}

Metformin is an antihyperglycemic agent which has been in use for many decades. It exerts its action by inhibiting hepatic gluconeogenesis and improving the sensitivity of insulin in skeletal muscles via adenosine monophosphate kinase. ${ }^{58}$ It also reduces low-density lipoprotein cholesterol and triglycerides. ${ }^{59}$ The main mechanism of weight loss may be by reduction of insulin resistance and suppression of appetite. ${ }^{60}$ Increased level of glucagon-like peptide-1 (GLP-1) may contribute.

A meta-analysis by Mizuno et al showed a mean difference of $-3.17 \mathrm{~kg}(95 \% \mathrm{CI}:-4.44$ to $-1.90 \mathrm{~kg})$ in the metformin group compared to placebo. ${ }^{57}$ Individual RCTs have shown that the placebo group gains weight over time, while the metformintreated group had lost weight. A recent meta-analysis of 12 studies reported a $-3.27 \mathrm{~kg}(95 \% \mathrm{CI}:-4.66$ to -1.89$)$ mean change in weight between metformin and placebo. ${ }^{61}$ The dose used in the trials ranged from 750 to $1,500 \mathrm{mg}$ /day.

\section{Aripiprazole}

Aripiprazole has partial agonist activity at dopamine D2 and serotonin 5-HT1A receptors and antagonist activity at serotonin 5-HT2A receptors. Meta-analysis of three RCTs of aripiprazole as an add-on weight-reducing agent reported a mean difference of $-2.13 \mathrm{~kg}(95 \% \mathrm{CI}:-2.87$ to $-1.39 \mathrm{~kg})$ compared to placebo. ${ }^{57}$ One of the RCTs with positive results was a large multicontinental study where aripiprazole was added to clozapine. ${ }^{15}$ In addition to weight loss, significant reduction in total and low-density lipoprotein cholesterol was observed in the aripiprazole group. The other advantage is that aripiprazole is an antipsychotic.

\section{Topiramate}

The antiepileptic medication, topiramate, has shown promising results in managing AIWG. Topiramate exerts its action of weight loss by stimulating lipoprotein lipase while inhibiting carbonic anhydrase and lipogenesis. It also suppresses appetite and increases satiety. ${ }^{62}$

Topiramate reduced olanzapine-induced weight gain in healthy male volunteers who received olanzapine for 14 days. ${ }^{63}$ Low baseline thyrotropin hormone levels predicted the amount of weight gained and topiramate was particularly effective in reducing weight gain in this subgroup. A 10-week study of patients with olanzapine-induced weight gain showed a weight change of $-4.4 \mathrm{~kg}$ in the topiramatetreated group compared to placebo $(+1.2 \mathrm{~kg}) \cdot{ }^{64}$ An interesting observation was that patients who gained the highest amount of weight during the treatment showed the highest amount of weight loss with topiramate. A study by Ko et al using topiramate 100 or $200 \mathrm{mg}$ established a dose-response relationship for weight loss. ${ }^{65}$ There is evidence that topiramate may exert therapeutic effects on psychotic states, which may be explained by antagonism of glutamate-induced excito-toxicity at $\alpha$-amino-3-hydroxy-5-methyl-4-isoxazolepropionic acid receptor (AMPA) and kainate receptors. ${ }^{66}$ However, caution is required when administering the drug as the side effects may mimic features of mental illness.

\section{Norepinephrine reuptake inhibitors}

Norepinephrine reuptake inhibitors (NRIs) act by inhibiting the reuptake of norepinephrine. They are postulated to reduce appetite, causing weight loss. Poyurovsky et al conducted two RCTs where reboxetine was added on in patients treated with olanzapine. Both trials reported significantly lower weight gain in the reboxetine add-on group compared to placebo. ${ }^{67,68}$ A study of atomoxetine did not yield positive results. ${ }^{69}$ The cardiovascular side effects of changes in blood pressure and heart rate with NRIs may counteract the benefits of weight loss.

\section{Sibutramine}

Sibutramine has been withdrawn from the market following a clinical trial that demonstrated increased cardiovascular risk. It also worsens symptoms of psychosis. Sibutramine exerts its action by inhibiting the reuptake of norepinephrine and serotonin. It promotes release of dopamine by exocytosis that results in increased extracellular dopamine. The two small RCTs of sibutramine yielded contrasting results. One study reported significant weight loss $(3.8 \mathrm{vs} 0.8 \mathrm{~kg})^{70}$ and another reported nonsignificant results ( $1.9 \mathrm{vs} 0.5 \mathrm{~kg}){ }^{71}$ Another RCT which compared sibutramine and metformin with placebo for 12 weeks did not show significant results. ${ }^{72}$

\section{d-Fenfluramine}

d-Fenfluramine, an anorectic drug, exerts its action by strengthening the serotonergic function in the brain. d-Fenfluramine 
releases serotonin through a carrier-dependent mechanism. Goodall et al conducted the only RCT to examine the effect of d-fenfluramine on antipsychotic-induced weight gain. ${ }^{73}$ d-Fenfluramine administered to overweight patients with schizophrenia on depot antipsychotics showed significant weight reduction compared to placebo. This drug was removed from the US market in 1997 after reports of heart valve disease and pulmonary hypertension.

\section{Zonisamide}

Exact mechanism of action of the novel antiepileptic drug zonisamide is unknown. It may act by altering the fast inactivation threshold of voltage-dependent sodium channels. It also reduces sustained high-frequency repetitive firing of action potentials and inhibits low-threshold T-type calcium channels in neurons. An RCT conducted by Ghanizadeh et al demonstrated that zonisamide resulted in modest, but significant reduction of AIWG. ${ }^{74}$

\section{Amantadine}

Amantadine increases the synthesis and release of dopamine with some inhibition of the reuptake of dopamine. It is also an $N$-methyl-D-aspartate receptor antagonist. ${ }^{75}$ An RCT of 21 adults who had gained at least $5 \mathrm{lb}$ with olanzapine showed significantly less weight gain in the amantadinetreated group. ${ }^{76}$ Another trial showed that amantadine 100-300 mg was effective in attenuating or promoting weight loss in patients who had olanzapine-induced weight gain. ${ }^{77}$ Amantadine is not known to worsen psychosis, although it has the potential to do so due to excessive dopaminergic action.

\section{$\mathrm{H} 2$ receptor antagonists}

$\mathrm{H} 2$ receptor antagonists such as famotidine and nizatidine are postulated to reduce weight by suppression of appetite secondary to increased cholecystokinin levels. ${ }^{78}$ Two RCTs reported that nizatidine did not cause significant weight loss in patients who gained weight due to olanzapine. ${ }^{78,79}$ However, an open-label study showed that nizatidine treatment resulted in significant weight loss and this correlated with leptin levels. ${ }^{80}$

\section{Medication combinations}

Two RCTs have investigated the effects of "polypills" or medication combinations in reducing weight gain. RCT of metformin-sibutramine combination did not show significant benefits. ${ }^{72}$ However, reboxetine-betahistine combination showed clinically meaningful attenuation of olanzapineinduced weight gain. $^{81}$

\section{Mifepristone}

Two trials conducted in lean, healthy men have shown that the glucocorticoid and progesterone antagonist mifepristone is effective in reducing weight gain in patients treated with risperidone or olanzapine. ${ }^{82}$

\section{Modafinil}

Modafinil exerts its action by stimulating monoaminergic receptors. One RCT showed that modafinil resulted in significantly less weight gain compared to placebo in patients treated with olanzapine. ${ }^{83}$ This trial was of short duration (3 weeks) and only 20 in each group completed the trial. A pilot study investigating the effect of modafinil in stabilized patients on clozapine did not find any difference in metabolic parameters or weight compared to placebo. ${ }^{84}$

\section{Betahistine}

Betahistine is a histaminergic $\mathrm{H} 1$ receptor agonist and $\mathrm{H} 3$ antagonist which has been investigated as a co-treatment for olanzapine-induced weight gain. Weight-reducing potential of betahistine has been linked to its action on hypothalamus and liver to induce thermogenesis and reduce food intake. ${ }^{85,86} \mathrm{An} \mathrm{RCT}$ in 48 healthy females who received co-treatment with olanzapine and betahistine reported a $37 \%$ reduction in the mean weight gain in the betahistine group. An added benefit was the reduction in Epworth sleepiness scores in the treatment group. ${ }^{87}$ Betahistine alone or in combination with reboxetine has been shown to be significantly effective in reducing the weight gained on olanzapine in two small RCTs. ${ }^{81,88}$

\section{GLP-I analogs}

GLP-1 is a gut hormone synthesized in the intestinal mucosa. GLP-1 stimulates glucose-induced insulin secretion in the pancreas and inhibits secretion of glucagon. Additionally, it reduces appetite and food intake by activating central and peripheral GLP-1 receptors. A meta-analysis showed that GLP-1 reduced weight in obese diabetic and nondiabetic patients, when compared to other antidiabetic drugs including metformin. ${ }^{89}$ A preclinical study on rats has demonstrated that GLP-1 reduces olanzapine-induced weight gain..$^{90}$

\section{Diethylpropion and phentermine}

Diethylpropion and phentermine are dopamine agonists which stimulate secretion of dopamine. They are postulated to increase the energy expenditure, leading to weight loss. Both these drugs are indicated for the short-term treatment of obesity. However, these two medications have not been studied for AIWG. ${ }^{91}$ 
Some antiobesity medications have not been investigated for treatment of AIWG. Rimonabant, a cannabinoid CB1 receptor antagonist, has been shown to reduce weight compared to placebo in obese individuals. ${ }^{92}$ However, it has been removed from the market due to risk of depression and suicidality. RCTs of amylin derivative pramlintide, serotonindopamine-NRI tesofensine and selective 5-HT2c agonist lorcaserin have shown promising results in reducing weight in healthy, obese individuals. An RCT combining the leptin analog metreleptin with pramlintide demonstrated better results than either alone. Some other combinations which have been studied are nalterexone/buproprion, buproprion/ zonisamide and phenteramine/topiramate. Fluoxetine, orlistat, L-carnitine, phenylpropanolamine and rosiglitazone have not shown any benefit.

\section{Discussion}

Almost all antipsychotics cause weight gain. Weight gain increases the risk of metabolic complications and physical ill health and can reduce compliance. Several strategies have been tried to reduce AIWG. Clinicians select antipsychotics based on patient preference, efficacy and side effects profile. Haloperidol, lurasidone, ziprasidone, aripiprazole and amisulpiride carry lesser risk of weight gain, compared to other antipsychotics. However, risk of AIWG is not the only factor which governs selection of antipsychotics. Clozapine, the medication with the highest risk of weight gain, is also the only antipsychotic so far licensed for treatment of resistant schizophrenia. Similarly, olanzapine which ranks high in terms of efficacy carries higher risk of weight gain than most other antipsychotics.

Since the risk of weight gain appears to be highest in the first year of treatment, careful monitoring and early intervention are the first step in managing AIWG.

The available data describe several strategies to attenuate AIWG. They are reducing the dose, switching to an antipsychotic with less weight gaining potential, adding pharmaceutical adjuvants and nonpharmacologic interventions. Selecting effective interventions is difficult as most studies have methodological limitations. They are of short duration, ranging from a few weeks to 6 months. Studies investigating strategies to prevent AIWG have included firstepisode patients. Other studies have investigated treatment of AIWG. The response may be different in these two groups. Other confounding factors such as genetic susceptibility to weight gain, sedentary lifestyles and other medications that the patient is prescribed will also influence the outcome.

Nonpharmacologic interventions are important in the management of AIWG. Dietary counseling, exercise interventions, cognitive and behavioral strategies appear to be equally effective as individual and group therapies. All patients who are commenced on antipsychotics should be routinely provided with nutritional counseling and advice about a healthy lifestyle. Those who gain weight should be enrolled in structured program which monitors the adherence of patients to the management plan. Nonpharmacologic interventions appear to be more effective in patients treated with antipsychotics with a high propensity for weight gain. There is some evidence that combining lifestyle modification and metformin is more effective than either intervention alone. ${ }^{93}$

Apart from a significant impact on cardio-metabolic risk factors, nonpharmacologic weight prevention or reduction has the potential to improve quality of life, antipsychotic medication adherence and overall prognosis of the illness.

Pharmacologic interventions with evidence of efficacy include reducing the dose of the offending medication, switching to another antipsychotic with less potential of weight gain and adding an adjuvant to reduce weight. There is evidence that switching to antipsychotics with lower risk of weight gain, such as haloperidol, lurasidone, ziprasidone, aripiprazole and amisulpiride, results in weight loss. However, the risk of relapse and the likelihood of emergence of other side effects such as extrapyramidal side effects must be considered. The other option is to add an adjuvant. Metformin is the most extensively studied adjuvant and has the best evidence. Evidence from meta-analysis suggests a mean difference of $3 \mathrm{~kg}$ over placebo in trials which lasted up to 24 weeks. This corresponds to about $1 \mathrm{~kg} / \mathrm{m}^{2}$ reduction of BMI. ${ }^{91}$ Weight loss of $\geq 7 \%$ is considered clinically meaningful. Evidence shows that metformin results in clinically significant weight loss in about half the patients. ${ }^{61}$ Metformin may be more effective in preventing AIWG in antipsychotic-naive patients. Effects of metformin beyond weight reduction, such as glycemic control, are also an advantage. Topiramate has less evidence, but may result in weight loss of about $4 \mathrm{~kg} .{ }^{57}$ It may have a therapeutic effect in patients with psychosis. ${ }^{57}$ Although orlistat is approved by the Food and Drug Administration as a weight-reducing agent, there is no evidence that it is effective in AIWG. The evidence regarding other adjuvant medications is inadequate to recommend their use in clinical practice.

The use of antipsychotics in children and adolescents has increased dramatically over the past few decades. It is alarming that children and adolescents gain more weight than their adult counterparts, which predisposes them to consequences of weight gain for many years. Weight gain in children has negative physical health as well as mental health 
consequences. Children and adolescents who are overweight can have issues with body image and self-esteem. Evidence for metformin in children is not as robust as in adults.

\section{Conclusion}

In conclusion, there is some evidence that switching to an antipsychotic with less risk of weight gain, lifestyle modification and adding an adjuvant such as metformin or topiramate may help prevent and treat AIWG. Combination of interventions may be helpful. Interventions will have to be tailored according to individual needs. Preventing weight gain in patients treated with antipsychotics should be considered a priority.

\section{Disclosure}

The authors report no conflicts of interest in this work.

\section{References}

1. De Hert M, Detraux J, van Winkel R, Yu W, Correll CU. Metabolic and cardiovascular adverse effects associated with antipsychotic drugs. Nat Rev Endocrinol. 2011;8(2):114-126.

2. Gami AS, Witt BJ, Howard DE, et al. Metabolic syndrome and risk of incident cardiovascular events and death: a systematic review and meta-analysis of longitudinal studies. J Am Coll Cardiol. 2007;49(4): 403-414.

3. Mitchell AJ, Vancampfort D, De Herdt A, Yu W, De Hert M. Is the prevalence of metabolic syndrome and metabolic abnormalities increased in early schizophrenia? A comparative meta-analysis of first episode, untreated and treated patients. Schizoph Bull. 2013;39(2):295-305.

4. Mitchell AJ, Vancampfort D, Sweers K, van Winkel R, Yu W, De Hert M. Prevalence of metabolic syndrome and metabolic abnormalities in schizophrenia and related disorders-a systematic review and meta-analysis. Schizophr Bull. 2013;39(2):306-318.

5. Olfson M, Gerhard T, Huang C, Crystal S, Stroup TS. Premature mortality among adults with schizophrenia in the United States. JAMA Psychiatry. 2015;72(12):1172-1181.

6. Fan Z, Wu Y, Shen J, Ji T, Zhan R. Schizophrenia and the risk of cardiovascular diseases: a meta-analysis of thirteen cohort studies. J Psychiatr Res. 2013;47(11):1549-1556.

7. Cotes RO, de Nesnera A, Kelly M, et al. Antipsychotic cardiometabolic side effect monitoring in a state community mental health system. Community Ment Health J. 2015;51(6):685-694.

8. Weissman E, Jackson C, Schooler N, Goetz R, Essock S. Monitoring metabolic side effects when initiating treatment with second-generation antipsychotic medication. Clin Schizophr Relat Psychoses. 2012;5(4): 201-207.

9. Allison DB, Mentore JL, Heo M, et al. Antipsychotic-induced weight gain: a comprehensive research synthesis. Am J Psychiatry. 1999; 156(11):1686-1696.

10. Leucht S, Cipriani A, Spineli L, et al. Comparative efficacy and tolerability of 15 antipsychotic drugs in schizophrenia: a multiple-treatments meta-analysis. Lancet. 2013;382(9896):951-962.

11. Rummel-Kluge C, Komossa K, Schwarz S, et al. Head-to-head comparisons of metabolic side effects of second generation antipsychotics in the treatment of schizophrenia: a systematic review and metaanalysis. Schizophr Res. 2010;123(2-3):225-233.

12. De Hert M, Yu W, Detraux J, Sweers K, van Winkel R, Correll CU. Body weight and metabolic adverse effects of asenapine, iloperidone, lurasidone and paliperidone in the treatment of schizophrenia and bipolar disorder: a systematic review and exploratory meta-analysis. CNS Drugs. 2012;26(9):733-759.
13. Bak M, Fransen A, Janssen J, van Os J, Drukker M. Almost all antipsychotics result in weight gain: a meta-analysis. PLoS One. 2014;9(4):e94112.

14. Tek C, Kucukgoncu S, Guloksuz S, Woods SW, Srihari VH, Annamalai A. Antipsychotic-induced weight gain in first-episode psychosis patients: a meta-analysis of differential effects of antipsychotic medications. Early Interv Psychiatry. 2016;10(3):193-202.

15. Fleischhacker WW, Heikkinen ME, Olie JP, et al. Effects of adjunctive treatment with aripiprazole on body weight and clinical efficacy in schizophrenia patients treated with clozapine: a randomized, doubleblind, placebo-controlled trial. Int J Neuropsychopharmacol. 2010;13(8): $1115-1125$.

16. Henderson DC, Vincenzi B, Andrea NV, Ulloa M, Copeland PM. Pathophysiological mechanisms of increased cardiometabolic risk in people with schizophrenia and other severe mental illnesses. Lancet Psychiatry. 2015;2(5):452-464.

17. Roerig JL, Steffen KJ, Mitchell JE. Atypical antipsychotic-induced weight gain: insights into mechanisms of action. CNS Drugs. 2011; 25(12):1035-1059.

18. Ak M, Sezlev D, Sutcigil L, Akarsu S, Ozgen F, Yanik T. The investigation of leptin and hypothalamic neuropeptides role in first attack psychotic male patients: olanzapine monotherapy. Psychoneuroendocrinology. 2013;38(3):341-347.

19. Hosojima H, Togo T, Odawara T, et al. Early effects of olanzapine on serum levels of ghrelin, adiponectin and leptin in patients with schizophrenia. J Psychopharmacol. 2006;20(1):75-79.

20. Lu ML, Wang TN, Lin TY, et al. Differential effects of olanzapine and clozapine on plasma levels of adipocytokines and total ghrelin. Prog Neuropsychopharmacol Biol Psychiatry. 2015;58:47-50.

21. Goncalves P, Araujo JR, Martel F. Antipsychotics-induced metabolic alterations: focus on adipose tissue and molecular mechanisms. Eur Neuropsychopharmacol. 2015;25(1):1-16.

22. Kristiana I, Sharpe LJ, Catts VS, Lutze-Mann LH, Brown AJ. Antipsychotic drugs upregulate lipogenic gene expression by disrupting intracellular trafficking of lipoprotein-derived cholesterol. Pharmacogenomics J. 2010;10(5):396-407.

23. Zhang JP, Lencz T, Zhang RX, et al. Pharmacogenetic associations of antipsychotic drug-related weight gain: a systematic review and metaanalysis. Schizophr Bull. 2016;42(6):1418-1437.

24. Correll CU, Manu P, Olshanskiy V, Napolitano B, Kane JM, Malhotra AK. Cardiometabolic risk of second-generation antipsychotic medications during first-time use in children and adolescents. JAMA. 2009;302(16):1765-1773.

25. Vandenberghe F, Gholam-Rezaee M, Saigi-Morgui N, et al. Importance of early weight changes to predict long-term weight gain during psychotropic drug treatment. J Clin Psychiatry. 2015;76(11):e1417-e1423.

26. Patel NC, Crismon ML, Hoagwood K, et al. Trends in the use of typical and atypical antipsychotics in children and adolescents. $J$ Am Acad Child Adolesc Psychiatry. 2005;44(6):548-556.

27. Pathak P, West D, Martin BC, Helm ME, Henderson C. Evidence-based use of second-generation antipsychotics in a state Medicaid pediatric population, 2001-2005. Psychiatr Ser. 2010;61(2):123-129.

28. Pringsheim T, Panagiotopoulos C, Davidson J, Ho J; CAMESA guideline group. Evidence-based recommendations for monitoring safety of second generation antipsychotics in children and youth. $J$ Can Acad Child Adolesc Psychiatry. 2011;20(3):218-233.

29. Ratzoni G, Gothelf D, Brand-Gothelf A, et al. Weight gain associated with olanzapine and risperidone in adolescent patients: a comparative prospective study. J Am Acad Child Adolesc Psychiatry. 2002;41(3): 337-343.

30. De Hert M, Dobbelaere M, Sheridan EM, Cohen D, Correll CU. Metabolic and endocrine adverse effects of second-generation antipsychotics in children and adolescents: a systematic review of randomized, placebo controlled trials and guidelines for clinical practice. Eur Psychiatry. 2011;26(3):144-158.

31. McCracken JT, McGough J, Shah B, et al; Research Units on Pediatric Psychopharmacology Autism Networks. Risperidone in children with autism and serious behavioral problems. $N$ Engl J Med. 2002;347(5): 314-321. 
32. Eapen V, John G. Weight gain and metabolic syndrome among young patients on antipsychotic medication: what do we know and where do we ssgo? Australas Psychiatry. 2011;19(3):232-235.

33. Weiden PJ, Mackell JA, McDonnell DD. Obesity as a risk factor for antipsychotic noncompliance. Schizophr Res. 2004;66(1):51-57.

34. Manschreck TC, Boshes RA. The CATIE schizophrenia trial: results, impact, controversy. Harv Rev Psychiatry. 2007;15(5):245-258.

35. Lieberman JA, Stroup TS, McEvoy JP, et al; Clinical Antipsychotic Trials of Intervention Effectiveness (CATIE) Investigators. Effectiveness of antipsychotic drugs in patients with chronic schizophrenia. $N$ Engl J Med. 2005;353(12):1209-1223.

36. Kinon BJ, Basson BR, Gilmore JA, Tollefson GD. Long-term olanzapine treatment: weight change and weight-related health factors in schizophrenia. J Clin Psychiatry. 2001;62(2):92-100.

37. Jonsdottir H, Opjordsmoen S, Birkenaes AB, et al. Predictors of medication adherence in patients with schizophrenia and bipolar disorder. Acta Psychiatr Scand. 2013;127(1):23-33.

38. Velligan DI, Weiden PJ, Sajatovic M, et al; Expert Consensus Panel on Adherence Problems in Serious and Persistent Mental Illness. The expert consensus guideline series: adherence problems in patients with serious and persistent mental illness. J Clin Psychiatry. 2009;70 (Suppl 4):1-46; quiz 47-48.

39. Faulkner G, Cohn T, Remington G. Interventions to reduce weight gain in schizophrenia. Schizophr Bull. 2007;33(3):654-656.

40. Fakhoury WK, Wright D, Wallace M. Prevalence and extent of distress of adverse effects of antipsychotics among callers to a United Kingdom National Mental Health Helpline. Int Clin Psychopharmacol. 2001; 16(3):153-162.

41. Lester H, Marshall M, Jones $\mathrm{P}$, et al. Views of young people in early intervention services for first-episode psychosis in England. Psychiatr Serv. 2011;62(8):882-887.

42. Angermeyer MC, Matschinger H. Neuroleptika und Lebensqualitat. Ergebnisse einer Patientenbefragung. [Neuroleptics and quality of life. A patient survey]. Psychiatr Prax. 2000;27(2):64-68. German.

43. Perkins DO. Adherence to antipsychotic medications. JClin Psychiatry. 1999;60 (Suppl 21):25-30.

44. Keller WR, Fischer BA, McMahon R, Meyer W, Blake M, Buchanan RW. Community adherence to schizophrenia treatment and safety monitoring guidelines. J Nerv Ment Dis. 2014;202(1):6-12.

45. Lasikiewicz N, Myrissa K, Hoyland A, Lawton CL. Psychological benefits of weight loss following behavioural and/or dietary weight loss interventions. A systematic research review. Appetite. 2014;72: $123-137$.

46. Warkentin LM, Das D, Majumdar SR, Johnson JA, Padwal RS. The effect of weight loss on health-related quality of life: systematic review and meta-analysis of randomized trials. Obes Rev. 2014;15(3): 169-182.

47. Evans S, Newton R, Higgins S. Nutritional intervention to prevent weight gain in patients commenced on olanzapine: a randomized controlled trial. Aust N Z J Psychiatry. 2005;39(6):479-486.

48. Grandy S, Fox KM, Hardy E; SHIELD Study Group. Association of weight loss and medication adherence among adults with type 2 diabetes mellitus: SHIELD (Study to Help Improve Early evaluation and management of risk factors Leading to Diabetes). Curr Ther Res Clin Exp. 2013;75:77-82.

49. Mukundan A, Faulkner G, Cohn T, Remington G. Antipsychotic switching for people with schizophrenia who have neuroleptic-induced weight or metabolic problems. Cochrane Database Syst Rev. 2010;(12): CD006629.

50. Barak Y, Aizenberg D. Switching to aripiprazole as a strategy for weight reduction: a meta-analysis in patients suffering from schizophrenia. J Obes. 2011;2011. pii: 898013. Epub 2010 Aug 25.

51. Stroup TS, McEvoy JP, Ring KD, et al; Schizophrenia Trials Network. A randomized trial examining the effectiveness of switching from olanzapine, quetiapine, or risperidone to aripiprazole to reduce metabolic risk: comparison of antipsychotics for metabolic problems (CAMP). Am J Psychiatry. 2011;168(9):947-956.
52. Stahl SM, Cucchiaro J, Simonelli D, Hsu J, Pikalov A, Loebel A. Effectiveness of lurasidone for patients with schizophrenia following 6 weeks of acute treatment with lurasidone, olanzapine, or placebo: a 6-month, open-label, extension study. J Clin Psychiatry. 2013;74(5): 507-515.

53. Cooper SJ, Reynolds GP, Barnes T, et al. BAP guidelines on the management of weight gain, metabolic disturbances and cardiovascular risk associated with psychosis and antipsychotic drug treatment. J Psychopharmacol. 2016;30(8):717-748.

54. Alvarez-Jimenez M, Hetrick SE, Gonzalez-Blanch C, Gleeson JF, McGorry PD. Non-pharmacological management of antipsychoticinduced weight gain: systematic review and meta-analysis of randomised controlled trials. Br J Psychiatry. 2008;193(2):101-107.

55. Bruins J, Jorg F, Bruggeman R, Slooff C, Corpeleijn E, Pijnenborg M. The effects of lifestyle interventions on (long-term) weight management, cardiometabolic risk and depressive symptoms in people with psychotic disorders: a meta-analysis. PLoS One. 2014;9(12):e112276.

56. Alvarez-Jimenez M, Gonzalez-Blanch C, Vazquez-Barquero JL, et al. Attenuation of antipsychotic-induced weight gain with early behavioral intervention in drug-naive first-episode psychosis patients: a randomized controlled trial. J Clin Psychiatry. 2006;67(8):1253-1260.

57. Mizuno Y, Suzuki T, Nakagawa A, et al. Pharmacological strategies to counteract antipsychotic-induced weight gain and metabolic adverse effects in schizophrenia: a systematic review and meta-analysis. Schizophr Bull. 2014;40(6):1385-1403.

58. Zhou G, Myers R, Li Y, et al. Role of AMP-activated protein kinase in mechanism of metformin action. J Clin Invest. 2001;108(8): $1167-1174$.

59. Wulffele MG, Kooy A, de Zeeuw D, Stehouwer CD, Gansevoort RT. The effect of metformin on blood pressure, plasma cholesterol and triglycerides in type 2 diabetes mellitus: a systematic review. $J$ Intern Med. 2004;256(1):1-14.

60. Lee A, Morley JE. Metformin decreases food consumption and induces weight loss in subjects with obesity with type II non-insulin-dependent diabetes. Obes Res. 1998;6(1):47-53.

61. de Silva VA, Dayabandara M, Wijesundara H, et al. Metformin for treatment of antipsychotic-induced weight gain in a South Asian population with schizophrenia or schizoaffective disorder: a double blind, randomized, placebo controlled study. J Psychopharmacol. 2015;29(12): $1255-1261$

62. Generali JA, Cada DJ. Topiramate: antipsychotic-induced weight gain. Hosp Pharm. 2014;49(4):345-347.

63. Evers SS, van Vliet A, van Vugt B, Scheurink AJ, van Dijk G. A low TSH profile predicts olanzapine-induced weight gain and relief by adjunctive topiramate in healthy male volunteers. Psychoneuroendocrinology. 2016;66:101-110.

64. Nickel MK, Nickel C, Muehlbacher M, et al. Influence of topiramate on olanzapine-related adiposity in women: a random, double-blind, placebocontrolled study. J Clin Psychopharmacol. 2005;25(3):211-217.

65. Ko YH, Joe SH, Jung IK, Kim SH. Topiramate as an adjuvant treatment with atypical antipsychotics in schizophrenic patients experiencing weight gain. Clin Neuropharmacol. 2005;28(4):169-175.

66. Afshar H, Roohafza H, Mousavi G, et al. Topiramate add-on treatment in schizophrenia: a randomised, double-blind, placebo-controlled clinical trial. J Psychopharmacol. 2009;23(2):157-162.

67. Poyurovsky M, Isaacs I, Fuchs C, et al. Attenuation of olanzapineinduced weight gain with reboxetine in patients with schizophrenia: a double-blind, placebo-controlled study. Am J Psychiatry. 2003;160(2): 297-302.

68. Poyurovsky M, Fuchs C, Pashinian A, et al. Attenuating effect of reboxetine on appetite and weight gain in olanzapine-treated schizophrenia patients: a double-blind placebo-controlled study. Psychopharmacology. 2007;192(3):441-448.

69. Ball MP, Warren KR, Feldman S, McMahon RP, Kelly DL, Buchanan RW. Placebo-controlled trial of atomoxetine for weight reduction in people with schizophrenia treated with clozapine or olanzapine. Clin Schizophr Relat Psychoses. 2011;5(1):17-25. 
70. Henderson DC, Copeland PM, Daley TB, et al. A double-blind, placebocontrolled trial of sibutramine for olanzapine-associated weight gain. Am J Psychiatry. 2005;162(5):954-962.

71. Henderson DC, Fan X, Copeland PM, et al. A double-blind, placebocontrolled trial of sibutramine for clozapine-associated weight gain. Acta Psychiatr Scand. 2007;115(2):101-105.

72. Baptista T, Uzcategui E, Rangel N, et al. Metformin plus sibutramine for olanzapine-associated weight gain and metabolic dysfunction in schizophrenia: a 12-week double-blind, placebo-controlled pilot study. Psychiatry Res. 2008;159(1-2):250-253.

73. Goodall E, Oxtoby C, Richards R, Watkinson G, Brown D, Silverstone T. A clinical trial of the efficacy and acceptability of D-fenfluramine in the treatment of neuroleptic-induced obesity. $\mathrm{Br} \mathrm{J}$ Psychiatry. 1988;153:208-213.

74. Ghanizadeh A, Nikseresht MS, Sahraian A. The effect of zonisamide on antipsychotic-associated weight gain in patients with schizophrenia: a randomized, double-blind, placebo-controlled clinical trial. Schizophr Res. 2013;147(1):110-115.

75. Blanpied TA, Clarke RJ, Johnson JW. Amantadine inhibits NMDA receptors by accelerating channel closure during channel block. J Neurosci. 2005;25(13):3312-3322.

76. Graham KA, Gu H, Lieberman JA, Harp JB, Perkins DO. Doubleblind, placebo-controlled investigation of amantadine for weight loss in subjects who gained weight with olanzapine. The American Journal of Psychiatry. 2005;162(9):1744-1746.

77. Deberdt W, Winokur A, Cavazzoni PA, et al. Amantadine for weight gain associated with olanzapine treatment. Eur Neuropsychopharmacol. 2005;15(1):13-21.

78. Assuncao SS, Ruschel SI, Rosa Lde C, et al. Weight gain management in patients with schizophrenia during treatment with olanzapine in association with nizatidine. Rev Bras Psiquiatr. 2006;28(4):270-276.

79. Cavazzoni P, Tanaka Y, Roychowdhury SM, Breier A, Allison DB. Nizatidine for prevention of weight gain with olanzapine: a doubleblind placebo-controlled trial. Eur Neuropsychopharmacol. 2003; 13(2):81-85.

80. Atmaca M, Kuloglu M, Tezcan E, Ustundag B. Nizatidine treatment and its relationship with leptin levels in patients with olanzapine-induced weight gain. Human Psychopharmacol. 2003;18(6):457-461.

81. Poyurovsky M, Fuchs C, Pashinian A, Levi A, Weizman R, Weizman A Reducing antipsychotic-induced weight gain in schizophrenia: a doubleblind placebo-controlled study of reboxetine-betahistine combination. Psychopharmacology (Berl). 2013;226(3):615-622.
82. Gross C, Blasey CM, Roe RL, Allen K, Block TS, Belanoff JK. Mifepristone treatment of olanzapine-induced weight gain in healthy men. Adv Ther. 2009;26(10):959-969.

83. Roerig JL, Steffen KJ, Mitchell JE, Crosby RD, Gosnell BA. An exploration of the effect of modafinil on olanzapine associated weight gain in normal human subjects. Biol Psychiatry. 2009;65(7):607-613.

84. Henderson DC, Freudenreich O, Borba CP, et al. Effects of modafinil on weight, glucose and lipid metabolism in clozapine-treated patients with schizophrenia. Schizophr Res. 2011;130(1-3):53-56.

85. Lian J, Huang XF, Pai N, Deng C. Preventing olanzapine-induced weight gain using betahistine: a study in a rat model with chronic olanzapine treatment. PLoS One. 2014;9(8):e104160.

86. Lian J, Huang XF, Pai N, Deng C. Ameliorating antipsychotic-induced weight gain by betahistine: Mechanisms and clinical implications. Pharmacol Res. 2016;106:51-63.

87. Barak N, Beck Y, Albeck JH. Betahistine decreases olanzapineinduced weight gain and somnolence in humans. J Psychopharmacol. 2016;30(3):237-241.

88. Barak N, Beck Y, Albeck JH. A randomized, double-blind, placebocontrolled pilot study of betahistine to counteract olanzapine-associated weight gain. J Clin Psychopharmacol. 2016;36(3):253-256.

89. Vilsboll T, Christensen M, Junker AE, Knop FK, Gluud LL. Effects of glucagon-like peptide-1 receptor agonists on weight loss: systematic review and meta-analyses of randomised controlled trials. BMJ 2012;344:d7771.

90. Lykkegaard K, Larsen PJ, Vrang N, Bock C, Bock T, Knudsen LB. The once-daily human GLP-1 analog, liraglutide, reduces olanzapineinduced weight gain and glucose intolerance. Schizophr Res. 2008; 103(1-3):94-103.

91. Fiedorowicz JG, Miller DD, Bishop JR, Calarge CA, Ellingrod VL, Haynes WG. Systematic review and meta-analysis of pharmacological interventions for weight gain from antipsychotics and mood stabilizers. Curr Psychiatry Rev. 2012;8(1):25-36.

92. Pi-Sunyer FX, Aronne LJ, Heshmati HM, Devin J, Rosenstock J; Group RI-NAS. Effect of rimonabant, a cannabinoid-1 receptor blocker, on weight and cardiometabolic risk factors in overweight or obese patients: RIO-North America: a randomized controlled trial. JAMA. 2006; 295(7):761-775.

93. Wu RR, Zhao JP, Jin H, et al. Lifestyle intervention and metformin for treatment of antipsychotic-induced weight gain: a randomized controlled trial. JAMA. 2008;299(2):185-193.
Neuropsychiatric Disease and Treatment

\section{Publish your work in this journal}

Neuropsychiatric Disease and Treatment is an international, peerreviewed journal of clinical therapeutics and pharmacology focusing on concise rapid reporting of clinical or pre-clinical studies on a range of neuropsychiatric and neurological disorders. This journa is indexed on PubMed Central, the 'PsycINFO' database and CAS,

\section{Dovepress}

and is the official journal of The International Neuropsychiatric Association (INA). The manuscript management system is completely online and includes a very quick and fair peer-review system, which is all easy to use. Visit http://www.dovepress.com/testimonials.php to read real quotes from published authors. 